\title{
Zależność pomiędzy wynikami badań przesiewowych wykonywanych w okresie noworodkowym i szkolnym
}

\section{Relationship between the result of newborn hearing screening and school-entry hearing screening test results}

\author{
Marika Kruszyńska ${ }^{1}$, Krzysztof Kochanek ${ }^{1,2}$, Adam Piłka², Henryk Skarżyński ${ }^{2}$ \\ ${ }^{1}$ Uniwersytet Marii Curie-Skłodowskiej, Wydział Humanistyczny, Zakład Logopedii i Językoznawstwa \\ Stosowanego, Lublin \\ ${ }^{2}$ Instytut Fizjologii i Patologii Słuchu, Światowe Centrum Słuchu, Kajetany
}

Adres autora: Marika Kruszyńska, Os. Ks. Mazowieckich 21/16, 06-500 Mława, e-mail: marikakru@wp.pl

\section{Streszczenie}

\begin{abstract}
Wstęp: Od ponad 10 lat prowadzony jest w Polsce program powszechnych badań przesiewowych słuchu u noworodków, a od kilku lat $\mathrm{w}$ coraz większej skali programy badań przesiewowych u dzieci w wieku szkolnym, realizowane we współpracy Instytutu Fizjologii i Patologii Słuchu oraz Kasy Rolniczego Ubezpieczenia Społecznego (KRUS). Badania przesiewowe słuchu u noworodków służą wczesnemu wykryciu wrodzonych wad słuchu, natomiast badania w wieku szkolnym - zaburzeń słuchu nabytych oraz wrodzonych, które ujawniają się w okresie późniejszym. Z uwagi na fakt, że wspomniane programy badań przesiewowych słuchu u dzieci w wieku szkolnym realizowane są przez Instytut od roku 2008 istnieje możliwość porównania wybranych parametrów obu programów w tej samej grupie dzieci.
\end{abstract}

Cel: Ocena zależności pomiędzy wynikami badań przesiewowych wykonanych u dzieci w okresie noworodkowym i w wieku szkolnym.

Materiał i metoda: Materiał pracy obejmował grupę ok. 60000 dzieci obojga płci, z różnych województw, które miały wykonane badania przesiewowe w okresie noworodkowym i szkolnym. W badaniach przesiewowych słuchu u noworodków stosowano badanie otoemisji akustycznych, natomiast $\mathrm{u}$ dzieci $\mathrm{w}$ wieku szkolnym audiometryczne badanie słuchu w zakresie częstotliwości od $500 \mathrm{~Hz}$ do $8000 \mathrm{~Hz}$.

Wyniki: Częstość wyników dodatnich w okresie noworodkowym wynosiła 0,9\%, natomiast u dzieci w wieku szkolnym $14 \%$. Porównanie wyników badań wykonywanych w okresie szkolnym i noworodkowym wykazało, że u noworodków z dodatnim wynikiem badania przesiewowego 2,5-krotnie częściej niż u dzieci z ujemnym wynikiem badania w okresie noworodkowym występuje nieprawidłowy wynik badania słuchu wykonanego w wieku szkolnym. Co więcej, u dzieci z dodatnim wynikiem badania przesiewowego $\mathrm{w}$ okresie noworodkowym progi słyszenia są gorsze niż u tych z wynikiem ujemnym.

Wnioski: W badaniach przesiewowych słuchu dzieci w wieku szkolnym nieprawidłowy wynik badania przesiewowego występuje znacznie częściej niż w badaniu przesiewowym u noworodków. U dzieci z dodatnim wynikiem badania przesiewowego w okresie noworodkowym znacznie częściej niż u dzieci z wynikiem ujemnym występuje dodatni wynik badania przesiewowego słuchu w wieku szkolnym.

Słowa kluczowe: badania przesiewowe słuchu • badania słuchu u dzieci w wieku szkolnym

Abstract

Background: A universal newborn hearing screening program has been carried out in Poland for more than 10 years, and in recent years there is also a school-age hearing screening program whose scale is steadily growing. This program has been introduced by the Institute of Physiology and Pathology of Hearing in cooperation with the Agrarian Social Insurance Fund (KRUS). Newborn hearing screening is useful for detecting congenital, permanent hearing loss, while school-age hearing screening facilitates detecting acquired hearing loss, which can be temporary, permanent, or congenital but develops after birth. Due to the fact that school-age hearing screening is a new program and is carried out only since 2008 , there is a need to compare essential outcome parameters of booth programs in the same group of children. 
Aims: The main purpose of this study is to compare selected parameters of both programs and determine the relationship between the results of both types of hearing screening programs.

Material and methods: In this work, we used the material from a group of almost 60000 children, of both genders, from different provinces, who underwent newborn and school-age hearing screening. The examination in newborn hearing screening consisted of otoacoustic emissions. The examination in school-age hearing screening consisted of an audiometric hearing screening test in the frequency range from 500 to $8000 \mathrm{~Hz}$.

Results: In newborn hearing screening there was $0,9 \%$ of positive results, however in school-age hearing screening there was $14 \%$ of positive results. The comparison of school-age and newborn hearing results shows that in school children with positive test results of newborn hearing screening there are 2,5 times more positive results in school-age screening. Moreover, hearing thresholds determined in the school-age screening program were generally worse in group of children with positive results of newborn hearing screening than in the children who had negative results in newborn hearing screening.

Conclusions: There are more positive results in school-age hearing screening than in newborn hearing screening. School-age hearing results shows that in school children with positive test results of newborn hearing screening there are more positive results in school-age screening.

Key words: hearing screening $\bullet$ school-age hearing screening

\section{Wprowadzenie}

Powszechne badania przesiewowe słuchu u noworodków zostały wdrożone do praktyki klinicznej w Polsce przez Fundację Wielka Orkiestra Świątecznej Pomocy (WOŚP) w 2002 roku [1]. Jednak prace związane $\mathrm{z}$ opracowaniem metod i procedur badań przesiewowych rozpoczęto wcześniej, ponieważ już w latach 1995-1998 Instytut Fizjologii i Patologii Słuchu realizował projekt zamawiany przez Ministra Zdrowia, którego wynikiem było opracowanie procedur, metod i urządzeń do badań przesiewowych [2-5]. Dzięki wdrożeniu programu Fundacji WOŚP, badaniami przesiewowymi objęte są obecnie prawie wszystkie nowonarodzone dzieci [1]. Podobnie jak w innych krajach, również w Polsce statystyki programu pokazują, że częstość wrodzonych zaburzeń słuchu u noworodków wynosi od 1 do 2 na 1000 [6].

Wiele czynników sprawia, że wraz z wiekiem wzrasta odsetek nabytych zaburzeń słuchu u dzieci. Są to m.in. infekcje górnych dróg oddechowych, wysiękowe zapalenie ucha, hałas środowiskowy, a także urazy spowodowane np. nieumiejętnym czyszczeniem ucha oraz uszkodzenia słuchu związane ze stosowaniem leków ototoksycznych [7-9]. Wzrost częstości występowania zaburzeń słuchu u dzieci w wieku szkolnym wynika również z faktu, że niektóre wrodzone wady słuchu ujawniają się w okresie późniejszym $[10,11]$. U dzieci w wieku szkolnym odsetek zaburzeń słuchu wynosi ponad 14\% [12-18].

Wyniki prac dotyczących efektywności badań przesiewowych jednoznacznie wskazują na konieczność wykonywania badań przesiewowych zarówno u noworodków, jak i u dzieci w wieku szkolnym [7,15,18-23]. Tylko wczesne wykrycie i zdiagnozowanie niedosłuchu u dzieci, niezależnie od wieku, umożliwia wczesną terapię i rehabilitację [15-17,21,24-27].

W Polsce w latach 2008-2011, w ramach współpracy Instytutu Fizjologii i Patologii Słuchu oraz Kasy Rolniczego Ubezpieczenia Społecznego (KRUS), zrealizowano programy badań przesiewowych słuchu u dzieci w wieku szkolnym ze środowisk wiejskich. W niektórych miastach prowadzone były również programy finansowane ze środków samorządów lokalnych. Biorąc pod uwagę fakt, że od 2002 roku realizowany jest program powszechnych badań przesiewowych słuchu u noworodków, można założyć, że znaczący odsetek dzieci urodzonych w latach 2002-2004 został objęty nie tylko badaniami przesiewowymi słuchu wykonywanymi w okresie noworodkowym, lecz także badaniami w wieku szkolnym [2].

\section{Cel}

Celem niniejszej pracy była analiza zależności między wynikami badań przesiewowych słuchu wykonanych w okresie noworodkowym i szkolnym u tych samych dzieci.

\section{Materiał i metoda}

W pracy zostały wykorzystane wyniki badań słuchu uzyskane podczas programu badań przesiewowych słuchu u dzieci w wieku szkolnym, realizowanego przez Instytut Fizjologii i Patologii Słuchu w Warszawie we współpracy z KRUS-em w roku szkolnym 2010/2011. Badania objęły grupę 80368 dzieci obojga płci, w wieku 7 lat. Z grupy tej, na podstawie wyników ankiety skierowanej do rodziców, wyodrębniono 59390 dzieci, u których badanie przesiewowe wykonano zarówno w okresie noworodkowym, jak i szkolnym. Rodzice wskazywali również w ankiecie, jaki był wynik badania przesiewowego w okresie noworodkowym (dodatni lub ujemny). Wynik dodatni w badaniu przesiewowym słuchu u noworodków oznacza, że nieprawidłowy wynik badania uzyskano przynajmniej $\mathrm{w}$ jednym uchu. $\mathrm{W}$ grupie dzieci $\mathrm{z}$ dodatnim wynikiem badania w okresie noworodkowym znalazło się 520 dzieci, natomiast w grupie z ujemnym wynikiem 58870 dzieci.

W badaniach przesiewowych słuchu u noworodków zastosowano otoemisje akustyczne wywoływane trzaskiem $[3,6,19,22,24,28-30]$, natomiast $w$ badaniach przesiewowych u dzieci w wieku szkolnym progową audiometrię tonalną dla przewodnictwa powietrznego w zakresie częstotliwości od $500 \mathrm{~Hz}$ do $8000 \mathrm{~Hz}$. W badaniach dzieci w wieku szkolnym stosowano urządzenie o nazwie Platforma Badań Zmysłów [31,32]. Wynik badania 
Tabela 1. Częstość wyników dodatnich badania przesiewowego u noworodków oraz wyników dodatnich uzyskanych podczas badań w szkole w poszczególnych województwach

Table 1. Percentage of positive results in newborn hearing screening and incorrect results obtained in school-age hearing screening in different provinces

\begin{tabular}{lcc}
\hline \multirow{2}{*}{ Województwo } & \multicolumn{2}{c}{ Odsetek wyników dodatnich } \\
\cline { 2 - 3 } & $\begin{array}{c}\text { W okresie } \\
\text { noworodkowym }\end{array}$ & $\begin{array}{c}\text { W badaniu } \\
\text { szkolnym }\end{array}$ \\
\hline dolnośląskie & $1,0 \%$ & $11,6 \%$ \\
\hline kujawsko-pomorskie & $0,8 \%$ & $11,2 \%$ \\
\hline lubelskie & $1,0 \%$ & $12,8 \%$ \\
\hline lubuskie & $1,0 \%$ & $12,0 \%$ \\
\hline tódzkie & $1,2 \%$ & $12,3 \%$ \\
\hline małopolskie & $0,6 \%$ & $15,4 \%$ \\
\hline mazowieckie & $0,9 \%$ & $16,7 \%$ \\
\hline opolskie & $1,5 \%$ & $13,2 \%$ \\
\hline podkarpackie & $0,7 \%$ & $16,8 \%$ \\
\hline podlaskie & $1,3 \%$ & $15,5 \%$ \\
\hline pomorskie & $1,1 \%$ & $15,0 \%$ \\
\hline śląskie & $0,9 \%$ & $12,4 \%$ \\
\hline świętokrzyskie & $0,7 \%$ & $14,1 \%$ \\
\hline warmińsko-mazurskie & $1,0 \%$ & $16,4 \%$ \\
\hline wielkopolskie & $0,6 \%$ & $9,4 \%$ \\
\hline zachodniopomorskie & $1,1 \%$ & $18,9 \%$ \\
\hline w całym materiale & $0,9 \%$ & $14,0 \%$ \\
\hline
\end{tabular}

przesiewowego w okresie szkolnym uznawano za prawidłowy (ujemny), jeżeli progi słyszenia dla wszystkich częstotliwości w obu uszach nie przekraczały $20 \mathrm{~dB}$ HL. Dla dzieci w wieku szkolnym wyznaczono średnie wartości ubytków słuchu dla częstotliwości 1000, 2000 i $4000 \mathrm{~Hz}$.

Analizę wyników badań przeprowadzono z wykorzystaniem programu Bazy Wiedzy - naukowej platformy informatycznej służącej do przetwarzania wyników badań przesiewowych Instytutu Fizjologii i Patologii Słuchu. Ocenę częstości występowania wyników nieprawidłowych badania przesiewowego słuchu w okresie szkolnym w odniesieniu do informacji uzyskanych na podstawie badania ankietowego, dotyczącego wyniku badania przesiewowego słuchu w okresie noworodkowym, wykonano z wykorzystaniem testu Chi-kwadrat Pearsona. Z uwagi, iż analiza charakterystyki rozkładu średnich ubytków słuchu, przeprowadzona za pomocą testu Shapiro-Wilka, nie miała cech rozkładu normalnego, analizę porównawczą wykonano z wykorzystaniem nieparametrycznego testu U Manna-Whitneya. Dla obu testów przyjęto, że różnice są istotne statystycznie dla poziomu istotności p<0,05.

\section{Wyniki}

Analiza danych przedstawionych w tabeli 1 wykazała, że odsetek dzieci $\mathrm{z}$ dodatnim wynikiem badania
Tabela 2. Odsetek wyników dodatnich w badaniach przesiewowych słuchu wykonywanych w wieku szkolnym u dzieci z dodatnim i ujemnym wynikiem badania przesiewowego słuchu w okresie noworodkowym

Table 2. Percentage of positive results in school-age hearing screening in the groups of children that tested positively and negatively in newborn hearing screening

\begin{tabular}{lc}
\hline \multicolumn{1}{c}{ Grupa } & $\begin{array}{c}\text { Odestek wyników } \\
\text { dodatnich w badaniach } \\
\text { przesiewowych } \\
\text { wykonanych w szkole }\end{array}$ \\
\hline $\begin{array}{l}\text { dzieci z ujemnym wynikiem } \\
\text { badania przesiewowego w okresie } \\
\text { noworodkowym (n=58 870) }\end{array}$ & $13,8 \%$ \\
\hline $\begin{array}{l}\text { dzieci z dodatnim wynikiem } \\
\text { badania przesiewowego w okresie } \\
\text { noworodkowym (n=520) }\end{array}$ & $34,8 \%$ \\
\hline
\end{tabular}

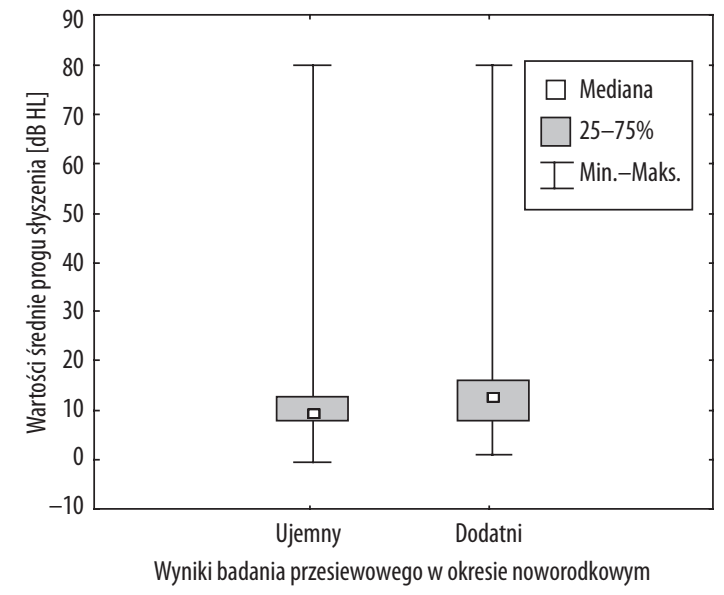

Rycina 1. Porównanie średnich wartości ubytków słuchu u dzieci z dodatnim i ujemnym wynikiem badania przesiewowego w okresie noworodkowym

Figure 1. Comparison of mean values of hearing loss in children with positive and negative results of newborn hearing screening

przesiewowego wykonanego w okresie noworodkowym wahał się w poszczególnych województwach od $0,6 \%$ do $1,5 \%$. W całym materiale odsetek wyników dodatnich wynosił $0,9 \%$. W tej samej grupie dzieci odsetek wyników dodatnich w badaniu przesiewowym wykonanym w okresie szkolnym wyniósł prawie $14 \%$.

W tabeli 2 przedstawiono odsetek dodatnich wyników badań przesiewowych wykonywanych u dzieci w wieku szkolnym, w grupach dzieci z dodatnim i ujemnym wynikiem badania przesiewowego słuchu w okresie noworodkowym. W obu rodzajach badań przesiewowych wynik dodatni oznaczał, że w jednym uchu lub obojgu uszach otrzymano nieprawidłowy wynik badania. W grupie dzieci z dodatnim wynikiem badania przesiewowego w okresie noworodkowym nieprawidłowy wynik badania przesiewowego wykonanego w okresie szkolnym występował 
u 34,8\% dzieci, natomiast w grupie dzieci z ujemnym wynikiem badania przesiewowego u 13,8\% dzieci. Analiza statystyczna wykazała, że różnice te są istotne statystycznie $(\mathrm{p}<0,05)$. Zatem u dzieci, które uzyskały wynik dodatni w badaniu przesiewowym wykonywanym w okresie noworodkowym, stwierdzono 2,5 razy częściej wynik dodatni $\mathrm{w}$ badaniu w wieku szkolnym niż u dzieci z ujemnym wynikiem badania przesiewowego w okresie noworodkowym.

Na rycinie 1 przedstawiono medianę, zakres 2 i 3 kwartyla oraz rozstęp średnich wartości ubytków słuchu łącznie dla prawego i lewego ucha, uzyskanych w grupach dzieci z dodatnim i ujemnym wynikiem badania przesiewowego wykonanego w okresie noworodkowym. Niezależnie od wyniku badania przesiewowego zakres średnich ubytków słuchu wynosił nawet 80 dB HL.

Analiza statystyczna wykazała, że u dzieci z dodatnim wynikiem badania przesiewowego w okresie noworodkowym średnie wartości progu słyszenia w okresie szkolnym są istotnie statystycznie wyższe niż u dzieci z ujemnym wynikiem badania przesiewowego.

\section{Dyskusja}

Zasadniczym celem pracy była ocena zależności pomiędzy wynikami badań przesiewowych słuchu wykonanych w okresie noworodkowym i szkolnym w tej samej grupie dzieci oraz analiza stanu słuchu u 7-latków, które uzyskały dodatni wynik badania przesiewowego w okresie noworodkowym.

Ze statystyk programów badań przesiewowych wynika, że odsetek wyników prawdziwie dodatnich wynosi ok. 1-2\%o $[3,17-21,33]$. Do tej grupy należą dzieci z obustronnym ubytkiem słuchu większym niż 40 dB HL. Około 45\% dzieci $z$ tej grupy ma znaczne lub głębokie wrodzone ubytki słuchu $[9-11,27]$. W analizowanym materiale nie stwierdzono u dzieci z dodatnim wynikiem badania przesiewowego w okresie noworodkowym przypadków znacznych i głębokich ubytków słuchu. Można zatem założyć, że dzieci z dodatnim wynikiem badania przesiewowego w okresie noworodkowym, które w okresie szkolnym uzyskały prawidłowy wynik badania słuchu, należą do grupy noworodków z wynikami fałszywie dodatnimi [12,19,25]. Część wyników fałszywie dodatnich można wiązać zapewne z pozostałościami płynu owodniowego w uszach noworodków lub też z innymi czynnikami, które wpłynęły na wynik badania (chociażby hałas otoczenia) [19,28]. Jak pokazują wyniki uzyskane przez różnych badaczy, zmniejszenie liczby wyników fałszywie dodatnich można osiągnąć przez wprowadzenie do procedury badania przesiewowego, badania słuchowych potencjałów wywołanych pnia mózgu - ABR [3,17,19,20,33].

W związku z powyższym założono, że odsetek nieprawidłowych wyników badania słuchu wykonywanego w okresie szkolnym powinien być praktycznie taki sam u dzieci z dodatnim i ujemnym wynikiem badania przesiewowego wykonanego w okresie noworodkowym. Zaskakujący jest zatem fakt, że u dzieci z dodatnim wynikiem badania przesiewowego wykonanego w okresie noworodkowym nieprawidłowy wynik badania słuchu w wieku szkolnym wystepował 2,5 raza częściej niż u dzieci z ujemnym wynikiem badania przesiewowego w okresie noworodkowym. Można postawić ostrożną tezę, której udowodnienie wymaga dalszych badań, że dzieci, które uzyskały dodatni wynik badania przesiewowego w okresie noworodkowym, należą do grupy, w której częściej występują czynniki predysponujące do zaburzeń słuchu w okresie szkolnym, czego potwierdzeniem jest wysoki odsetek wyników dodatnich $\mathrm{w}$ tej grupie dzieci uzyskany w badaniach przesiewowych w okresie szkolnym.

Badania przesiewowe noworodków mają na celu wykrycie wad wrodzonych, natomiast badania w wieku szkolnym, w których stosowane są metody audiometryczne, pozwalają wykryć wszelkiego rodzaju wady słuchu - wrodzone i nabyte $[1,8,9,12,18,21,22,34]$. Najczęściej są to niedosłuchy typu przewodzeniowego, spowodowane infekcjami ucha czy też przerostem migdałków podniebiennych $[7,8,26]$. Ale mogą to być również zaburzenia słuchu typu odbiorczego. Odsetek zaburzeń słuchu wzrasta wraz z wiekiem dziecka [11-17,35], co znalazło potwierdzenie również w wynikach niniejszej pracy.

Jak wykazano w niniejszej pracy, średnie wartości progu słyszenia w grupie dzieci, które w okresie noworodkowym uzyskały wynik fałszywie dodatni, były wyższe niż u dzieci, które uzyskały ujemny wynik badania przesiewowego w okresie noworodkowym, a dodatni w wieku szkolnym. Wynik ten jest zaskakujący, a wyjaśnienie zaobserwowanych zależności na podstawie uzyskanych wyników nie jest możliwe.

Wyniki przeprowadzonych badań w pełni potwierdzają słuszność wykonywania badań przesiewowych u dzieci w wieku szkolnym, pozwalających wykryć nabyte wady słuchu, najczęściej o typie przewodzeniowym, które, jak wiadomo, daje się skutecznie leczyć, jeśli są wcześnie wykryte [7,26].

Przeprowadzone w niniejszej pracy badania pokazały, że dodatni wynik badania przesiewowego w okresie noworodkowym może mieć znaczenie przy prognozowaniu częstszych niż u dzieci z wynikiem ujemnym zaburzeń słuchu w okresie szkolnym. Oznacza to, że jeśli u dziecka stwierdza się dodatni wynik badania przesiewowego w okresie noworodkowym, to należy zwrócić szczególną uwagę na jego rozwój słuchowy w okresie szkolnym. Dlatego prowadzenie obu programów przesiewowych słuchu jest tak istotne dla wczesnego wykrywania różnego rodzaju zaburzeń słuchu u dzieci w różnym wieku.

\section{Wnioski}

1. U dzieci w wieku szkolnym nieprawidłowy wynik badania przesiewowego słuchu występuje znacznie częściej niż w badaniu przesiewowym słuchu u noworodków.

2. U dzieci z wynikiem dodatnim badania przesiewowego w okresie noworodkowym znacznie częściej niż u dzieci z wynikiem ujemnym występuje wynik dodatni badania przesiewowego słuchu w wieku szkolnym.

3. Średnie wartości progów słyszenia u dzieci w wieku szkolnym są wyższe u tych dzieci, które uzyskały nieprawidłowy wynik badania przesiewowego w okresie noworodkowym. 


\section{Piśmiennictwo:}

1. Wróbel M, Szyfter W. Program Powszechnych Przesiewowych Badań Słuchu u Noworodków w Polsce. Postępy w Chirurgii Głowy i Szyi, 2011; 2: 56-59.

2. Kochanek K. Historia badań przesiewowych. Instytut Fizjologii Patologii Słuchu w Warszawie, 2011; http://www.ifps.pl/

3. Skarżyński H, Mueller-Malesińska M, Kochanek K i wsp. Metody stosowane do badań przesiewowych słuchu u noworodków. Audiofonologia, 1997; XI: 139-46.

4. Mueller-Malesińska M, Kochanek K, Skarżyński H, Ratyńska J, Senderski A, Sopliński P i wsp. Program powszechnych badań przesiewowych noworodków pod kątem wczesnego wykrywania uszkodzeń słuchu - prezentacja wyników z lat 1995-1998. Audiofonologia, 1999; XV: 75-82.

5. Mueller-Malesińska M, Ratyńska J, Kochanek, Skarżyński H. Perspektywy rozwoju badań przesiewowych słuchu u noworodków i niemowląt w Polsce. Audiofonologia, 1998; XIII: 223-28.

6. Fundacja Wielkiej Orkiestry Świątecznej Pomocy. Program powszechnych przesiewowych badań słuchu u noworodków. http://wosp.org.pl/medycyna/badania_sluchu

7. Hassmann-Poznańska E, Skotnicka B. Zapalenie ucha środkowego u dzieci. W: Śliwińska-Kowalska M, red. Audiologia Kliniczna. Łódź, Mediton, 2005; 379-90.

8. Goździewski A, Hassmann-Poznańska E, Skotnicka B, Piszcz M. Upośledzenie słuchu, jako następstwo przebytego wysiękowego zapalenia ucha. Otorynolaryngologia, 2009; 8(1): 28-32.

9. Mrugalska K, Kochanek K, Piłka A, Stefaniak A, Skarżyński H. Efektywność modelu badań przesiewowych słuchu u niemowląt z grupy wysokiego ryzyka, realizowanego przez niepubliczny zakład opieki zdrowotnej. Audiofonologia, 1999; XV: 91-100.

10. Korniszewski L. Niedosłuch w zespołach wad. W: Śliwińska-Kowalska M, red. Audiologia Kliniczna. Łódź, Mediton, 2005; 403-11.

11. Fortnum HM, Summerfield AQ, Marshall DH, Davis AC, Bamford JM. Prevalence of permanent childhood hearing impairment in the United Kingdom and implications for universal neonatal hearing screening: questionnaire based ascertainment study. BMJ, 2001; 323: 536-39.

12. Bamford J, Fortnum H, Bristow K, Smith J, Vamvakas G, Davies L i wsp. Systematic review of the effectiveness of school entry hearing screening. W: Current practice, accuracy, effectiveness and cost effectiveness of the school entry hearing screen. Health Technology Assesment, 2007; 11(32): 31-48.

13. Piotrowska A, Skarżyński H. European Consensus Statement on Hearing Screening of Pre-School and School-Age Children. Int J Pediatr Otorhinolaryngol, 2012; 76(1): 120-21.

14. Piotrowska A, Skarżyński H. European consensus statement on hearing, vision, and speech screening in pre-school and school -age children. Journal of Hearing Science, 2011; 1(2): 89-90.

15. Konkluzja Rady Europejskiej dotycząca wyrównywania szans dzieci z zaburzeniami komunikacyjnymi. Official Journal of the European Union: http://eurlex.europa.eu/LexUriServ/LexUriServ.do?uri=OJ: C: 2011: 361: 0009: 0010: EN: PDF

16. McCann DC, Worsfold S, Law CM, Mullee M, Petrou S, Stevenson J i wsp. Reading and communication skills after universal newborn screening for permanent childhood hearing impairment. W: McCann DC, Worsfold S, Law CM. Arch Dis Child, 2009; 94: 293-97.

17. Pastorino G, Sergi P, Mastrangelo M, Ravazzani P, Tognola G, Parazzini M i wsp. The Milan Project: A newborn hearing screeaning programme. Acta Pediatrica, 2005; 94: 458-63.
18. Weber BA, Diefendor A. Newborn Hearing Screening. W: Musiek FE, Rintelmann WF. Contemporary perspectives in hearing assessment, 1999; 327-47.

19. Clemens CJ, Davis SA. Minimizing False-Positives in Universal Newborn Hearing Screening: A Simple Solution. Pediatrics, 2001; 107: 3-29.

20. Kochanek K. Badania obiektywne. Portal Edukacyjny Instytutu Fizjologii i Patologii Słuchu. http://www.edu.ifps.org.pl

21. Kochanek K. Badania przesiewowe słuchu. W: Śliwińska-Kowalska M, red. Audiologia Kliniczna. Łódź, Mediton, 2005; 391-96.

22. Skarżyński H, Mueller-Malesińska M, Kochanek K, Geremek A, Senderski A, Ratyńska J. Modele powszechnych badań przesiewowych noworodków pod kątem występowania wad słuchu. Audiofonologia, 1997; XI: 173-82.

23. Dedhia K, Kitsko D, Sabo D, Chi DH. Children with sensorineural hearing loss after passing the newborn hearing screen. JAMA, 2013; 139(2): 119-23.

24. Hall JW III, Smith SD, Popelka GR. Newborn Hearing Screening with Combined Otoacoustic Emissions and Auditory Brainstem Responses. J Am Acad Audiol, 2004; 15: 414-25.

25. Niskar AS, Kieszak SM, Holmes A, Esteban E, Rubin C, Brody DJ. Prevalence of hearing loss among children 6 to 19 years of age. W: The Third National Health and Nutrition Examination Survey. JAMA, 1998; 279(14): 1071-75.

26. Obrębowski A, Obrębowska Z. Wpływ przewlekłego wysiękowego zapalenia ucha środkowego na rozwój mowy dzieci. Otorynolaryngologia, 2009; 8(4): 159-62.

27. Verhaert N, Willems M, Van Kerschaver E, Desloovere C. Impact of early hearing screening and treatment on language development and education level: Evaluation of 6 years of universal newborn hearing screening (ALGO) in Flanders, Belgium. Int J Pediatr Otorhinolaryngol, 2008; 72: 599-608.

28. Robinette MS. Clinical observations with envoked otoacoustic emission at Mayo Clinic. J Am Acad Audiol, 2003; 14(4): 215.

29. Ratyńska J, Mueller-Malesińska M, Kochanek K, Skarżyński H. Zastosowanie techniki OAE i ABR w badaniach przesiewowych i diagnostyce uszkodzeń słuchu u noworodków i niemowląt. Audiofonologia, 1999; XV: 29-33.

30. Jędrzejczak WW, Hatzopoulos S, Sliwa L, Pilka E, Kochanek K, Skarzynski H. Otoacoustic emissions in neonates measured with different acquisition protocols. Int J Pediatr Otorhinolaryngol, 2012; 76(3): 382-87.

31. Skarżyński H, Czyżewski A, Senderski A. Badania przesiewowe słuchu u dzieci i młodzieży w wieku szkolnym I. Tester słuchu „Słyszę...”. Audiofonologia, 2001; XX: 199-208.

32. Zapert A. Wiarygodność audiometrycznych badań przesiewowych słuchu wykonywanych w szkołach. Praca magisterska na Wydziale Nauki o Zdrowiu Warszawskiego Uniwersytetu Medycznego, 2011.

33. American Academy of Audiology. Childhood Hearing Screening Guideliness. 2011; 24 http://www.cdc.gov/ncbddd/hearingloss/documents/AAA_Childhood\%20Hearing\%20Guidelines_2011.pdf

34. Piłka E, Trzaskowski B, Jędrzejczak WW, Kochanek K, Skarżyński H. Ocena możliwości wykorzystania emisji otoakustycznych w badaniach przesiewowych słuchu u dzieci szkolnych w wieku 6-13 lat. W: Otorynolaryngologia - przegląd kliniczny, 2012; 11(1): 7-12.

35. Skarżyński PH, Kochanek K, Skarżyński H, Senderski A, Wysocki J, Szkiełkowska A i wsp. Hearing Screening Program in School-Age Children in Western Poland. Journal of International Advanced Otology, 2011; 7(2): 194-200. 